Guest Editorial, part of a Special Feature on Balancing Ecology and Community using Cumulative Effects Models

\title{
Cumulative Effects Assessment: Linking Social, Ecological, and Governance Dimensions
}

\author{
Marian Weber $^{1}, \underline{\text { Naomi Krogman }}^{2}$, and Terry Antoniuk ${ }^{3}$
}

\begin{abstract}
Setting social, economic, and ecological objectives is ultimately a process of social choice informed by science. In this special feature we provide a multidisciplinary framework for the use of cumulative effects assessment in land use planning. Forest ecosystems are facing considerable challenges driven by population growth and increasing demands for resources. In a suite of case studies that span the boreal forest of Western Canada to the interior Atlantic forest of Paraguay we show how transparent and defensible methods for scenario analysis can be applied in data-limited regions and how social dimensions of land use change can be incorporated in these methods, particularly in aboriginal communities that have lived in these ecosystems for generations. The case studies explore how scenario analysis can be used to evaluate various land use options and highlight specific challenges with identifying social and ecological responses, determining thresholds and targets for land use, and integrating local and traditional knowledge in land use planning. Given that land use planning is ultimately a value-laden and often politically charged process we also provide some perspective on various collective and expert-based processes for identifying cumulative impacts and thresholds. The need for good science to inform and be informed by culturally appropriate democratic processes calls for well-planned and multifaceted approaches both to achieve an informed understanding of both residents and governments of the interactive and additive changes caused by development, and to design action agendas to influence such change at the ecological and social level.
\end{abstract}

Key Words: cumulative effects; forest ecosystems; governance; scenario models; social indicators

\section{INTRODUCTION}

Land use planning is a 'wicked problem' that necessitates marrying science with stakeholder engagement and developing new tools to understand the interactive and additive impacts of development on community and environmental values. Scenario planning aspires to combine current local, traditional, and scientific knowledge with scenarios of future change to better manage decisions and risk (e.g., Dale et al. 2000, Prato 2007). This future-oriented approach allows the social, economic, and environmental implications of proposed activities, in this case alternative land management options, to be considered so that social and technical guidance on desirable, and undesirable, outcomes can be obtained. It also allows residents, in some cases, to be proactive as opposed to reactive in regard to the development they wish to encourage in their region as well as the quality of life, as represented by social, economic, and ecological targets, they wish to achieve.

Although scenario analysis can inform the nature of desired future development it is fraught with challenges. Scenario analysis in a land management context relies on the discipline of landscape ecology to inform the relationship between ecological indicators and landscape change. However, the social impacts of development on communities are more difficult to understand. Many of the transformations in communities that are meaningful are hard to detangle from broader societal changes and attribute to changes in landscape per se. In addition some of the most important indicators of community health related to governance, empowerment, and social issues tend to be outside the scope of land use planning. Finally, even within the scope of considerations within land use planning, scenario analysis is insufficient for making difficult trade-off decisions because ultimately the governance and policy institutions for land management determine how these results will be used. These challenges are particularly acute in aboriginal communities whose identity is tied to the land and who in many cases depend directly on the land for food, cultural, and spiritual needs. These communities are of special interest not only because of their traditional and contemporary land use and land relationships, but because of the governance issues raised by their comprehensive land claims and Aboriginal rights. Aboriginal communities have limited information on the status of various social, economic, and ecological indicators in their communities and thus lack the capacity to represent their interests on equal footing within technocratic assessment approaches.

In this special feature we explore a range of issues in the science, social, and governance dimensions of cumulative effects assessment and management. The key messages are organized around the themes of scenario analysis; incorporation of social indicators in land use decisions; understanding thresholds, adaptive capacity, and resilience; and governance and decision making in land use planning.

\footnotetext{
${ }^{1}$ Alberta Innovates - Technology Futures, ${ }^{2}$ Department of Resource Economics and Environmental Sociology, University of Alberta, ${ }^{3}$ Salmo Consulting Inc.
} 


\section{SCENARIO ANALYSIS}

Scenario analysis is a fundamental component of cumulative effects assessment (Duinker and Greig 2007), strategic environmental assessment (Gunn and Noble 2009), and land use planning (Kennett 2010). Scenarios are plausible, but structurally different descriptions of how the future might unfold (Mahmoud et al. 2009). A variety of computer simulation models have been used for scenario analysis to help managers and stakeholders evaluate complex and uncertain futures (e.g., Ive et al. 1989, Recatala et al. 2000, Peterson et al. 2003, Prato 2007, Greene et al. 2010). These models can bring communities, resource users, managers, and other interested stakeholders together to discuss and synthesize their current understanding and hypotheses of future change. The papers in this feature by Carlson et al. (2011), and Francis and Hamm (2011) show how empirically derived responses of ecological, social, and economic indicators to landscape change provide a framework to understand change that can be used in combination with landscape simulation models to evaluate practical options for land and resource planning. Their case studies show how such models have been used to empower remote aboriginal communities, in turn enhancing local capacity to develop resource management strategies. The Carlson et al. (2011) paper addresses the common constraint faced in these communities of limited availability of knowledge and tools for comparing the future performance of land use options. The challenge can be acute in developing regions such as Paraguay's Atlantic forest where funding for research is scarce. Carslon et al. (2011) show that even in datalimited contexts scenario planning still provides a flexible approach for making land use decisions, and that by identifying the underlying issues of land degradation, certain land use strategies can be prioritized, providing justification, in this case, to support small-holder farmers in conservation agriculture

The Francis and Hamm (2011) paper was able to test the recommendations of a land use plan against a 100-year model that simulates a number of land use impacts in relation to scale of oil and gas exploration and production, and expected economic benefits. The scenario model was able to support the land use zoning and cumulative effects recommendations in the North Yukon Regional Land Use Plan, which ultimately assisted the Yukon Government and the Vuntut Gwichin in obtaining final approval and adoption of the plan. These two papers show that scenario modeling studies can be critical for providing a widely trusted approach to understanding additive and interactive land use impacts, and instill confidence in stakeholders that certain high-impact land uses can be gauged appropriately to mitigate negative outcomes.

\section{INCORPORATION OF SOCIAL INDICATORS}

Dynamic landscape models originated in the field of ecology to assess the influence of combined changes, i.e., cumulative effects, resulting from natural biophysical variability and land use on ecological indicators such as species, communities, and processes (e.g., Mladenoff 2004). Recently, they have been expanded to include social and economic processes and indicators (Schneider et al. 2003, 2007, and Carlson et al. 2007). The paper by Mitchell and Parkins (2011) provides a "lessons learned" synopsis on social indicators as applied to cumulative effects models. This paper was informed by a workshop that gathered leading sociologists and Canadian social scientists who study social impacts of resource development to assess the validity of incorporating social indicators in cumulative effects models.

Although much has been done to better understand the social dimension of cumulative effects, empirical work has been lacking on social indicators that could be used as measurable inputs or outputs for cumulative effects models in different kinds of communities and regions. As Mitchell and Parkins (2011) point out, drawing on the work of Force and Machlis (1997), social indicators are best understood as integrated pieces of information that can be situated in time and space. However in the practice of cumulative effects assessment the approach to social impacts is to select a "grab bag" of social indicators based on ease of obtaining available information. Cumulative effects assessment in practice also often fails to address deeper issues of community and regional well-being. Against this gap, social scientists are being asked to make reliable generalizations about functional, measurable relationships between certain social indicators and land use change or scenarios. As pointed out in most papers in this special feature, a vexing challenge is to truly design cumulative effects assessments to describe the dialectic relationship between ecological conditions and social and economic indicators so as to measure those most closely responsive to each other in communities under development pressure. This is particularly important for the scenario modeling approach because it relies on estimated partial correlative relationships among social, economic, and ecological indicators.

As pointed out in Mitchell and Parkins (2011), there is no consensus among social scientists on the treatment of social indicators and social "thresholds" in cumulative effects assessment. However the authors do provide a list of the top prioritized social indicators of well-being for measuring social impacts in areas near industrial or recreational developments. These include variables on equity, quality of life, and locus of governance control. The authors also recognize the tension between finding indicators that are comparable across regions and indicators that are sensitive to local priorities and relevant to local stakeholders. Importantly they hold that although long-term research is needed on social indicators and thresholds, time is also running out for many northern communities under intense development pressure. In our view, an implication of this paper is that social scientists should develop stronger theoretical approaches to understanding 
cumulative social impacts, i.e., how different social, economic, and ecological impacts interact to produce different outcomes, under different kinds of resource development, political, and cultural conditions. In particular, common property resource management theory, resilience theory, and political ecology may better inform how social indicators for cumulative effects assessment in a particular locale are chosen.

\section{THRESHOLDS, ADAPTIVE CAPACITY, AND RESILIENCE}

Ecological thresholds are defined as points where small changes in land use produce large nonlinear ecosystem responses (e.g., Holling 1973, Groffman et al. 2006). However, from a social perspective we might also be worried about social thresholds where small changes in land use produce discrete nonlinear responses in human well-being. There are many ways to conceive of social thresholds. They can be thought of as points at which there are large shifts in the resilience and adaptive capacity of communities, systemic cultural shifts, or simply the potential for noncompensatory losses of the kind associated with the loss of pristine ecosystems, spiritual sites, and opportunities for cultural practice. Thresholds as tipping points are distinguished from thresholds as a management approach used to identify limits of acceptable change and establish upper limits on environmental loss for the management of key outcomes around recreation, aquaculture, and land use (Stanky et al. 1984, Zeldis et al. 2006, Antoniuk et al. 2009).

Spyce et al. (2012) develop a case study in the Southeast Yukon region in Canada, which is experiencing unprecedented landscape change from forestry and energy development, to empirically test for discrete negative changes in well-being from development, and also to understand evidence to support limits to development. Their analysis considers the trade-offs between employment, population growth, hunting, and fishing that accompany development. They find that for the community as a whole, there is no 'threshold' level of development. However, the community overall prefers greater conservation than generated by the business as usual trajectory for land use. In addition, the aggregation of preferences at a community level masks important differences between individuals. An important caveat to the approach undertaken by Spyce et al. (2012) is that it assumes independence between the indicators selected to measure individual well-being. The Mitchell and Parkins (2011) piece points to the difficulty of empirically identifying social thresholds, given that it is the combination of social indicators, and how they interact, that influences variables such as equity, quality of life, and the locus of control of community members.

The empirical approach to thresholds in the Spyce et al. (2012) paper can be contrasted with that of Christensen and Krogman (2012) who provide a conceptualization of social thresholds based on a sociological analysis of social resilience. They define thresholds as collectively recognized points that signify new experiences. Unique to their approach is the stance that collective memory should inform a culturally responsive cumulative effects assessment. Collective memory is held in residents' mental maps of the places and historical markers of feedbacks in their social system from shifts in land use or conditions. They tested this approach in a case study exploring social and environmental impacts of resource development in a small Canadian Northern community. They find that local understandings of thresholds, particularly in communities in which long-term residents actively use the landscape for subsistence and resource-related employment, calls for an exploration of the signals that people identify as important to track for long-term change in the land and in their immediate environment. They hold that those signals represent the thresholds that residents view as critical for continued viable human relationships and environmental health, as well as for collective welfare improvements in the future. Residents in the community chose variables such as "power in decision making" and "level of healing" as social thresholds that represent capacity to act, hope, and build on a collective ability to care for each other and the land. This orientation is highly consistent with Howitt's (2001) work that argues that any study on social impacts must recognize common aboriginal priorities to care for country, people, and culture.

The Christensen and Krogman (2012) paper provides a novel approach to understanding how local knowledge can inform the development of social indicators, used in cumulative effects assessment and monitoring frameworks. Moreover they show how collective memory can help communities articulate what indicators of well-being in the community are desired and how desired outcomes should inform how thresholds, which tend to dwell on maintaining the status quo or some tolerable level of it, are chosen. By working with the community to reflect on changes in the past, community residents were able to backcast to how previous developments have appeared to foster or hinder the status of desirable community conditions, and this exercise further allowed those community members to link management practices to desirable industrial and land management practices.

Parlee et al. (2012) developed a similar approach to understand social-ecological thresholds in a community in northern Alberta where local expert interviews yielded perceived correlations and/or patterns of cause-effect between resource development activities and observed ecological change. These authors, like Christensen and Krogman (2012), suggest that local people need to first be able to reconstruct the history of ecological change to identify future tipping points that jeopardize a healthy resource base. In their paper, they describe thresholds as tipping points for both ecological and socioeconomic outcomes. Their study employs 23 interviews with Cree land users whose knowledge is rich around hunting, fishing, trapping, berry harvesting, medicinal plant gathering 
and who are able to articulate the influence of forestry, tourism, recreation, and agriculture on the quality and quantity of resources in their traditional territory. Parlee et al.'s findings reveal an interesting mix of embedded ecological and social changes associated with resource developments. A key challenge, they argue, in developing standardized approaches to cumulative social impact research, is the juggernaut of varied definitions of what represents a "healthy ecosystem" to varied stakeholders, and the lack of recognition that for native communities a health ecosystem may in fact constitute survival.

\section{GOVERNANCE AND DECISION MAKING}

There are a number of ways to incorporate value trade-offs in land use planning processes. Narrative and qualitative approaches are suitable for group deliberation and prioritization but are not amenable to informing the general public's preferences for trade-offs between competing values. Spyce et al. (2012) show how choice experiments can be used to evaluate community preferences for the futures that might result from alternative land use scenarios. The case study illustrates how individual preference for data over social and environmental indicators can be incorporated into simulation models to assist land use planners in setting land use objectives. In addition to the question of threshold identification a number of distributional issues of interest to governments and planners are explored including community preferences for intergenerational benefits and costs, and the degree of consensus around community values, particularly between aboriginal and nonaboriginal groups. The results show that the community values future benefits and costs as much as present day benefits of costs, an interesting conclusion aligned with attitudes in aboriginal communities on caring for future generations and the tie to place. Spyce et al. (2012) find considerable variation within the community around preferences for conservation suggesting that even where a conservation path might be preferred overall there could still be strong community opposition to limiting development. In addition, the opposition is unrelated to identifiable groups, e. g., employed versus unemployed, making it difficult to identify and compensate "losers" from a more conservative approach to land use.

The Spyce et al. (2012) paper shows how information can be used to inform planning decisions and identify potential barriers to planning decisions, but it does not address the actual process for making decisions. Although economic approaches such as choice experiments provide important insights with regard to public values and trade-offs, there are tensions between the use of technocratic approaches for decision making and the democratic impulses of civil society. Technocratic approaches tend to subordinate politics to science and decisionistic approaches tend to subordinate science to politics, with problematic outcomes in both cases. The contribution by Parkins (2011) presents a pragmatic approach that integrates public values and science in constructive ways through deliberative techniques such as consensus conferences and web-based small group discussions. It is argued that the pragmatic approach can inform several key stages of cumulative effects assessment, including an initial determination of land use preferences, an understanding of impact pathways, scenario analysis, and public policy recommendations. As a way of building bridges between the science of cumulative effects assessment, social choice, and public policy, Parkins (2011) offers a conceptual framework to understand the linkages between these distinct processes, and examines several case studies in the field of environment and resource management to learn about the possibilities for deepening democracy through cumulative effects assessment.

The pragmatic approach presented by Parkins (2011) is suitable for local and regional decision making. However the paper by Foote (2012) outlines some of the external constraints on local decision making, including global markets, and employment and economic outcomes at global scales, illustrating a continued gap in how to integrate cumulative effects management across different scales of drivers and outcomes. Focusing on the development of Canada's oil sands, Foote examines the issue of thresholds from an ecological, social, and governance perspective. Key to Foote's argument is the emphasis on the social question: to reliably do cumulative effects assessment, what is a reasonable time frame for recovery of an ecosystem from industrial impacts? When the time frame is 100 years or more, Foote questions the justification for tampering with an ecosystem to such an extent that current generations will not be able to see the ecosystem in recovery, or hold the developers accountable to promises made. This is not unlike the more elaborate argument by Freudenburg et al. (2008) in regard to the pattern of spreading costs, concentrating economic benefits, and hiding the real costs associated with other large scale industrial developments. From an ecological perspective, the thresholds are related to ecological risks associated with scientific uncertainty and potential irreversible losses of important and ancient peat land ecosystems from oil sands mining. From a social perspective, Foote focuses on the environmental and aboriginal concerns raised over oil sands mining and gaps in policy frameworks, and governance for managing regional thresholds in the face of global development pressures and competing necessities for energy and environment.

Finally, Rudel's (2011) paper expands on the linkages between local and regional decisions and global sustainability. $\mathrm{He}$ argues that there is tension and interplay between "defensive environmental actions" that follow from negative feedbacks that alert people to change their practices, e.g., switching to energy efficient technologies, and "altruistic environmental actions". "Altruistic environmental actions" are a response to thresholds or structural changes in a system, the 
transformation of which initiates a cascade of fundamental changes. An example might be the creation of the United Nations or the European community, both of which emerged after World War II. Rudel argues that cataclysmic events such as war and natural disaster can focus and reinforce defensive environmentalist behaviors and instill a sense of "common fate" among the larger population that strengthens local initiatives. The role of this paper is to remind us of the social learning that occurs across scales that can inform the perceived risks of certain large scale developments. The public response to avoid negative outcomes with defensive environmental actions is linked to focusing events such as the catastrophic consequences of the British Petroleum deep sea well blow out and oil spill. In the wake of the BP spill many Louisiana fishermen, for example, have carried out the defensive action to have more than one source of income, knowing that the income is vulnerable to pollution events. When varied and interactive defensive actions occur, Rudel describes this as a "multiphasic pattern of response" that can motivate significant social change where broader public demand is made for responses at high levels of decision making. This paper also brings into view the potential politicized role of cumulative social impact assessment to recognize past focusing events of related resource developments. The readiness of the population to demand more protection, at higher levels of government, i.e., altruistic environmentalism, may call for stronger policies that scrutinize development projects for their more long-term and pervasive risks to ecological integrity and human dignity.

\section{CONCLUSIONS}

In a suite of case studies that span the boreal forest of Western Canada to the interior Atlantic forests of Paraguay we show how the development of transparent and defensible methods for scenario analysis can be applied in data-limited regions and how to incorporate social dimensions of land use change, particularly in aboriginal communities. Issues around the identification and implementation of cumulative effects thresholds are explored along with local to global governance challenges. Together the papers provide approaches for measuring social, economic, and ecological indicator responses to change, e.g., developing dose-response functions; designing cross-sectional time-series studies on socioeconomic indicators to assess community capacity for change; and assessing preferences for alternative futures. Recommendations around the structure and inclusion of various collective processes to inform cumulative effects assessment are provided and highlight the unique role of aboriginal communities in identifying culturally relevant indicators for cumulative effects assessments that can be incorporated into various management decisions.

Although it is impossible to accurately predict the future, effective cumulative effects assessment and land use planning initiatives require an approach that combines our current local, traditional, and scientific knowledge with scenarios of future change so that social and technical guidance on desirable, and undesirable, outcomes can be obtained. Integrated cumulative effects assessment and management is best conducted as an iterative process between defining impacts and outcomes and stakeholder engagement and in defining their goals and aspirations, understanding change, and decision making. Together the papers provide a number of conclusions. First they highlight the need for ongoing political support to ensure that the combined scientific/public engagement process receives adequate resources to incorporate traditional and local knowledge and expertise, ensure that affected groups and individuals support modeling assumptions and findings, and revise simulations to reflect local input. Second, cumulative effects management requires a clear engagement process and rules that provide incentives and opportunities for stakeholders to participate in land use decisions. Further research and experimentation is needed to address technical and socio-political issues. Key gaps include: the development of transparent and defensible methods for developing scenarios and applying this approach in data-limited regions; valuing intangible and incommensurable ecological goods and services; incorporating social values and indicators that explore plausible outcomes while acknowledging that communities and individuals can choose alternate courses of action; and refining methods to communicate integrated modeling results with nontechnical participants.

The process of each approach to cumulative impact assessment has its weaknesses and strengths. Although most governments and industries tend to prefer quantitative approaches to cumulative impacts, rural communities are often calling for more culturally appropriate qualitative approaches. Although the quantitative approach will resonate with high level decision makers, the qualitative approach is more likely to invite citizen participation and eventual validation of the cumulative effects study in their community. One type of data, with one kind of expert interpretation, is increasingly politically unacceptable and methodologically weak from a social science perspective. Complimentary methods are required to fully embrace the nature of interactive and additive impacts of resource development, and to engage people in influencing the decisions that will greatly affect where they live. We hope that the studies and conceptual investigations included in this special feature will prompt further inquiry into the sustainability sciences, the methods of impact assessment, and at the core, a more informed set of approaches to sustain desired landscape conditions as well as community wellbeing.

Responses to this article can be read online at: http://www.ecologyandsociety.org/voll7/iss2/art22/ responses/ 


\section{Acknowledgments:}

We would like to thank Environment Canada, the Canadian International Development Agency, and Alberta Innovates Technology Futures for financial support of the research that appears in this special issue.

\section{LITERATURE CITED}

Antoniuk, T., S. Kennett, C. Aumann, M. Weber, S. Davis Schuetz, R. McManus, K. McKinnon, and K. Manuel. 2009. Valued component thresholds (management objectives) project. Environmental Studies Research Funds Report No. 172, ESRF, Calgary, Alberta, Canada. [online] URL: http://w ww.esrfunds.org/pdf/172.pdf

Carlson, M., E. Bayne, and B. Stelfox. 2007. Seeking a balance: assessing the future impacts of conservation and development in the Mackenzie Watershed. Canadian Boreal Initiative, Ottawa, Ontario, Canada.

Carlson, M. J., R. Mitchell, and L. Rodriguez. 2011. Scenario analysis to identify viable conservation strategies in Paraguay's imperiled Atlantic forest. Ecology and Society 16 (3): 8. http://dx.doi.org/10.5751/ES-04267-160308

Christensen, L., and N. Krogman. 2012. Social thresholds and their translation into social-ecological management practices. Ecology and Society 17(1): 5. a href="http://dx.doi.org/10.5751/ ES-04499-170105

Dale, V. H., S. Brown, R. A. Haeuber, N. T. Hobbs, N. Huntly, R. J. Naiman, W. E. Riebsame, M. G. Turner, and T. J. Valone. 2000. Ecological principles and guidelines for managing the use of land. Ecological Applications 10:639-670.

Duinker, P. N., and L. A. Greig. 2007. Scenario analysis in environmental impact assessment: improving explorations of the future. Environmental Impact Assessment Review 27:206-219. http://dx.doi.org/10.1016/j.eiar.2006.11.001

Foote, L. 2012. Threshold considerations and wetland reclamation in Alberta's mineable oil sands. Ecology and Society 17(1): 35. http://dx.doi.org/10.5751/ES-04673-170135

Force, J. E, and G. E. Machlis. 1997. The human ecosystem part II: social indicators in ecosystem management. Society \& Natural Resources 10:369-382. http://dx.doi.org/10.1080/089 41929709381035

Francis, S. R., and J. Hamm. 2011. Looking forward: using scenario modeling to support regional land use planning in Northern Yukon, Canada. Ecology and Society 16(4): 18. htt p://dx.doi.org/10.5751/ES-04532-160418

Freudenburg, W. R., R. Gramling, S. Laska, and K. T. Erikson. 2008. Organizing hazards, engineering disasters? Improving the recognition of political-economic factors in the creation of disasters. Social Forces 87:1015-1038. http://dx.doi.org/10 $\underline{.1353 / \text { sof. } 0.0126}$

Greene, R., J. E. Luther, R. Devillers, and B. Eddy. 2010. An approach to GIS-based multiple criteria decision analysis that integrates exploration and evaluation phases: case study in a forest-dominated landscape. Forest Ecology and Management 260:2102-2114. http://dx.doi.org/10.1016/j.foreco.2010.08.052

Groffman, P. M., J. S. Baron, T. Blett, A. J. Gold, I. Goodman, L. H. Gunderson, B. M. Levinson, M. A. Palmer, H. W. Paerl, G. D. Peterson, N. LeRoy Poff, D. W. Rejeski, J. F. Reynolds, M. G. Turner, K. C. Weathers, and J. Wiens. 2006. Ecological thresholds: the key to successful environmental management or an important concept with no practical application? Ecosystems 9:1-13. http://dx.doi.org/10.1007/s10021-003-0142$\underline{\mathrm{Z}}$

Gunn, J. H., and B. F. Noble. 2009. Integrating cumulative effects in regional strategic environmental assessment frameworks: lessons from practice. Journal of Environmental Assessment Policy and Management 11:267-290. http://dx.do i.org/10.1142/S1464333209003361

Holling, C. S. 1973. Resilience and stability of ecological systems. Annual Review of Ecology and Systematics 4:1-23. http://dx.doi.org/10.1146/annurev.es.04.110173.000245

Howitt, R. 2001. Rethinking resource management: justice, sustainability and indigenous peoples. Routledge, London, UK.

Ive, J. R., K. D. Cocks, and C. A. Parvey. 1989. Using the LUPIS land management package to select and schedule multi-site operations. Journal of Environmental Management 29:31-45.

Kennett, S. A. 2010. Fix it up: why and how to put northern land use planning on track for success. In T. Berger, S. A. Kennett, H. King. Canada's North: what's the plan? The Conference Board of Canada, Ottawa, Ontario, Canada.

Mahmoud M., Y. Liu, H. Hartmann, S. Stewart, T. Wagener, D. Semmens, R. Stewart, H. Gupta, D. Dominguez, F. Dominguez, D. Hulse, R. Letcher, B. Rashleigh, C. Smith, R. Street, J. Ticehurst, M. Twery, H. van Delden, R. Waldick, D. White, and L. Winter. 2009. A formal framework for scenario development in support of environmental decision-making. Environmental Modeling and Software 24:798-808. http://dx. doi.org/10.1016/j.envsoft.2008.11.010

Mitchell, R. E., and J. R. Parkins. 2011. The challenge of developing social indicators for cumulative effects assessment and land use planning. Ecology and Society 16(2): 29. [online] URL: http://www.ecologyandsociety.org/vol16/iss2/art29 
Mladenoff, D. J. 2004. LANDIS and forest landscape models. Ecological Modelling 180:7-19. http://dx.doi.org/10.1016/j.e colmodel.2004.03.016

Parkins, J. R. 2011. Deliberative democracy, institution building, and the pragmatics of cumulative effects assessment. Ecology and Society 16(3): 20. http://dx.doi.org/10.5751/ES04236-160320

Parlee, B. L., K. Geertsema, and Lesser Slave Lake Indian Regional Council. 2012. Social-ecological thresholds in a changing boreal landscape: insights from Cree knowledge of the Lesser Slave Lake region of Alberta, Canada. Ecology and Society 17(2): 20. http://dx.doi.org/10.5751/ES-04410-170220

Peterson, G. D., G. S. Cumming, and S. R. Carpenter. 2003. Scenario planning: a tool for conservation in an uncertain world. Conservation Biology 17:358-366. http://dx.doi.org/10 $.1046 / \mathrm{j} .1523-1739.2003 .01491 . \mathrm{x}$

Prato, T. 2007. Evaluating land use plans under uncertainty. Land Use Policy 24:165-174. http://dx.doi.org/10.1016/j.land usepol.2006.02.003

Recatala, L., J. R. Ive, I. A. Baird, N. Hamilton, and J. Sánchez. 2000. Land-use planning in the Valencian Mediterranean Region: Using LUPIS to generate issue relevant plans. Journal of Environmental Management 59:169-184. http://dx.doi.org/ $\underline{10.1006 / j e m a .2000 .0350}$

Rudel, T. K. 2011. Local actions, global effects? Understanding the circumstances in which locally beneficial environmental actions cumulate to have global effects. Ecology and Society 16(2): 19. [online] URL: http://www.ec ologyandsociety.org/vol16/iss2/art19/

Schneider, R., S. Boutin, J. Stelfox, and S. Wasel. 2007. Scenarios are plausible stories about the future, not forecasts. Ecology and Society 12(1): r4. [online] URL: http://www.eco logyandsociety.org/vol12/iss1/resp4/

Schneider, R. R., J. B. Stelfox, S. Boutin, and S. Wasel. 2003. Managing the cumulative impacts of land uses in the Western Canadian Sedimentary Basin: a modeling approach. Conservation Ecology 7(1): 8. [online] URL: http://www.con secol.org/vol7/iss 1/art8/

Spyce, A., M. Weber, and W. Adamowicz. 2012. Cumulative effects planning: finding the balance using choice experiments. Ecology and Society 17(1): 22. http://dx.doi.org /10.5751/ES-04491-170122

Stankey, G. H., S. F. McCool, and G. L. Stokes. 1984. Limits of acceptable change: a new framework for managing the Bob Marshall Wilderness Complex. Western Wildlands 10:33-37.

Zeldis, J., M. Felsing, and J. Wilson. 2006. Limits of acceptable change: a framework for managing environmental performance of New Zealand marine farming. Water \& Atmosphere 14:16-17. [online] URL:http://www.niwa.co.nz/p ublications/wa/vol14-no2-june-2006/limits-of-acceptable-changea-framework-for-managing-marine-farming 